\title{
Wing dimorphism in aphids
}

\author{
C Braendle ${ }^{1}$, GK Davis ${ }^{2}$, JA Brisson ${ }^{2}$ and DL Stern ${ }^{2}$ \\ ${ }^{1}$ Institut Jacques Monod, CNRS, Universités Paris 6 and 7, Tour 43, 2 place Jussieu, 75251 Paris cedex 05, France; ${ }^{2}$ Department of \\ Ecology E Evolutionary Biology, Princeton University, Princeton, NJ 08544, USA
}

\begin{abstract}
Many species of insects display dispersing and nondispersing morphs. Among these, aphids are one of the best examples of taxa that have evolved specialized morphs for dispersal versus reproduction. The dispersing morphs typically possess a full set of wings as well as a sensory and reproductive physiology that is adapted to flight and reproducing in a new location. In contrast, the nondispersing morphs are wingless and show adaptations to maximize
\end{abstract}

fecundity. In this review, we provide an overview of the major features of the aphid wing dimorphism. We first provide a description of the dimorphism and an overview of its phylogenetic distribution. We then review what is known about the mechanisms underlying the dimorphism and end by discussing its evolutionary aspects.

Heredity (2006) 97, 192-199. doi:10.1038/sj.hdy.6800863; published online 5 July 2006

Keywords: alternative phenotypes; aphids; phenotypic plasticity; wing polyphenism; wing polymorphism

\section{Aphid biology}

Aphids are small, soft-bodied insects of the order Hemiptera that feed on the fluid in plant phloem. Aphids exhibit complex life cycles. Approximately $10 \%$ of species alternate between a primary (usually woody) host plant and a secondary (herbaceous) host plant. Nonhost-alternating species are usually monophagous but may feed on a range of related host plants (Blackman and Eastop, 1994). Aphids display a high reproductive rate due to three peculiarities of their reproductive biology. First, during the spring and summer months, female aphids reproduce parthenogenetically, obviating the need for males. Second, during these parthenogenetic generations, the embryos initiate development immediately after the budding of the oocyte from the germarium and are born as fully developed first-instar nymphs (ie, they are viviparous). Finally, the oldest embryos also contain embryos, so that adult parthenogenetic aphids carry not only their daughters but also some of their granddaughters within them. During the fall, declining daily photoperiod and temperature induce the development of sexual females and males. These sexual aphids mate and females produce yolk-rich eggs that undergo diapause to survive the winter (ie, they are oviparous).

Different species of aphid may exhibit wing dimorphism at various stages of the life cycle. Here, we distinguish between environmentally induced dimorphism, known as polyphenism, and genetically determined dimorphism, known as polymorphism. Wing polyphenism occurs primarily among parthenogenetic females, while wing polymorphism has been found only in males. While the bulk of the discussion that follows concerns the female polyphenism, we end with a consideration of its relationship to the male polymorphism (Figure 1).

Correspondence: C Braendle, Institut Jacques Monod, CNRS, Universités Paris 6 and 7, Tour 43, 2 place Jussieu, 75251 Paris cedex 05, France. E-mail: braendle@ijm.jussieu.fr

Received 9 January 2006; accepted 1 June 2006; published online 5 July 2006

\section{Differences between winged and wingless aphid morphs}

The winged and wingless phenotypes in aphids differ in a range of morphological, physiological, life history and behavioural features. Besides having wings and functional flight muscles, the fully winged morph exhibits heavier sclerotization of head and thorax, more fully developed compound eyes, ocelli, longer antennae, more rhinaria, and sometimes larger siphunculi and cauda (Kalmus, 1945; Kring, 1977; Kawada, 1987; Miyazaki, 1987). Most of these differences reflect the different life styles of the two phenotypes, as the winged morphs are equipped with an elaborate sensory system for flight and host plant location. Consistent with this theme, winged forms are also more resistant to starvation (Tsuji and Kawada, 1987b; Hazell et al, 2005).

The morphological differences between winged and wingless phenotypes usually correlate with differences in life history. In general, the winged phenotype differs from the wingless phenotype by showing longer nymphal development, longer pre-reproductive adult period, longer reproductive period, lower offspring production, and prolonged longevity (Noda, 1960; MacKay and Wellington, 1975; Campbell and Mackauer, 1977; Tsuji and Kawada, 1987b; Tsumuki et al, 1990). In addition, in response to shortened photoperiod, winged females tend to produce mainly sexual females whereas wingless females produce both sexual females and males (MacKay et al, 1983; Nunes and Hardie, 1996).

\section{Phylogenetic distribution of wing dimorphisms}

Phylogenetic evidence indicates that the wingless form in aphids has been secondarily derived, as in most other insects. Within the Aphididae - comprising more than 95\% of all 4400 extant aphid species - there is extensive variation in the occurrence of winged and wingless morphs at different stages of the life cycle. Many species 

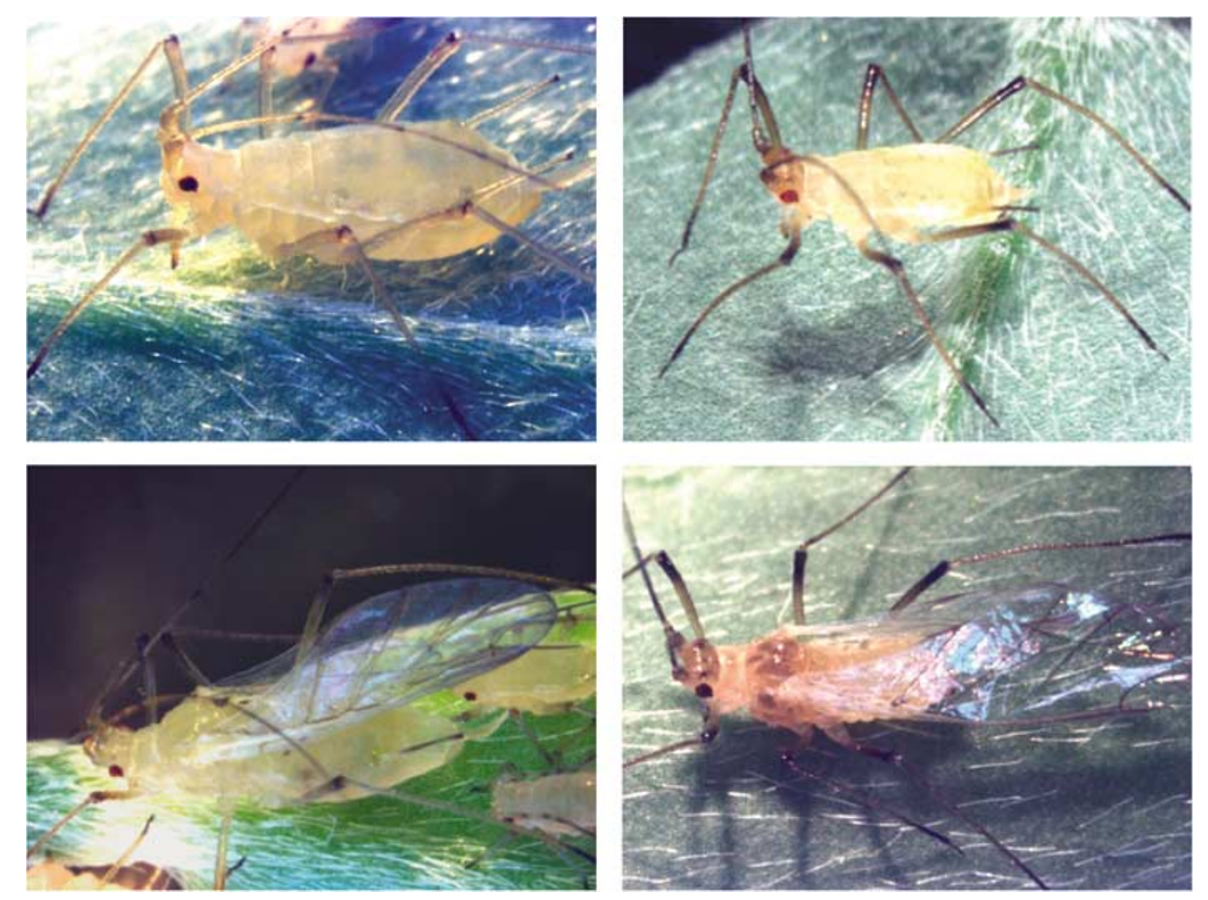

Figure 1 The female polyphenism (left) and male genetic polymorphism (right). In both cases, discrete alternative wingless (top) or winged (bottom) morphs are produced.

of the more primitive taxa, such as the Calaphidinae, produce only winged parthenogenetic females (Hille Ris Lambers, 1947, 1966; Heie, 1982). In some of these species, however, some winged females may differ in their flight capability or colonies may display variation in wing length (Hille Ris Lambers and van den Bosch, 1964; Hille Ris Lambers, 1966; Dixon, 1972; Heie, 1982; Heikinheimo, 1987). In Drepanosiphum dixoni, for example, all parthenogenetic females develop wings, yet some individuals lack indirect flight muscles and are therefore not capable of flight (Dixon, 1972). In other calaphidine species (eg, Symydobius oblongus) the parthenogenetic females show consistent differences in wing length, and the short-winged females do not fly (Heikinheimo, 1987). Most species of the Aphididae, however, produce both fully winged and completely wingless parthenogenetic females.

The diverse dispersal strategies of aphids appear to have evolved in association with two dominant ecological factors: host plant alternation and type of host plant. In host-alternating species, the morphs migrating between the primary and secondary hosts are always winged, whereas both winged and wingless females frequently occur during the parthenogenetic generations on the summer host for both host-alternating and nonhost-alternating species (Blackman and Eastop, 1994). Certain host plant characteristics, such as host plant persistence, may also correlate with the propensity to produce predominantly winged or wingless parthenogenetic females. Ephemeral host plants, including annual herbaceous hosts, can be exploited only temporarily and dispersal to new or more persistent hosts must take place at some point during the life cycle. Consistent with this idea, species feeding on large or perennial host plants may exhibit a lower incidence of winged morph production (Groeters, 1989). An exception are tree- dwelling aphid species, which often produce exclusively winged females compared to species feeding on herbaceous plants, possibly because flight allows aphids to find a suitable feeding location in architecturally complex trees (Waloff, 1983).

In most species the sexual females are wingless, with exceptions in more primitive taxa. Sexual males of Eriosomatinae, Anoeciinae, Hormaphidinae, and some Lachninae are wingless. In most other taxa males are winged; for example, the males of all host-alternating aphidines are winged (Blackman and Eastop, 1994, 2000). In about $10 \%$ of European species, however, both winged and wingless males have been recorded (Smith and MacKay, 1989). In the few species that have been examined in detail, this dimorphism is apparently caused by a genetic polymorphism (Hille Ris Lambers, 1966; Müller, 1969; Smith and MacKay, 1989).

\section{Mechanisms}

\section{Environmental cues}

The environmental conditions affecting the production of winged versus wingless morphs have been studied intensively (Hille Ris Lambers, 1966; Lees, 1966; Mittler and Sutherland, 1969; Kunkel and Kloft, 1974; Müller et al, 2001). Here, we briefly summarize the conditions known to cue production of the winged morph, focusing on parthenogenetic females.

Density (tactile stimulation): Density-dependent regulation of alternative dispersal phenotypes is common in aphids and other insects. Increased aphid density triggers wing formation in many species and in some species a small increase in density is sufficient (Bonnemaison, 1951; Johnson, 1965; Lees, 1967; 
Sutherland, 1969a,b; Shaw, 1970a). The proximate mechanism mediating these environmental conditions appears to be increased tactile stimulation between individual aphids (Johnson, 1965). However, it is possible that chemical cues play an additional minor role (Kunert and Weisser, 2005). While the location of the tactile receptors is not known, in some species perception is mediated mainly by the antennae (Johnson, 1965; Lees, 1967; Sutherland, 1969a).

Host plant quality (nutrition): For a given aphid clone, variation in winged morph production correlates with variation in host plant species (Vereschagina and Shaposhnikov, 1998) and with changes in host plant quality or host plant age (Sutherland, 1969b). However, a review by Müller et al (2001) showed that more than half of 38 examined studies in 12 different aphid species did not confirm the hypothesis that poor nutrition is responsible for an increase in winged morph production. In many of the earlier studies, the reported host plant effect on winged morph production was likely due to the effect of the host plant on the number of physical contacts between aphids (Müller et al, 2001). Nevertheless, a decrease in plant quality alone can trigger wing induction in some species (Müller et al, 2001).

Interspecific interactions: Interactions among different aphid species that aggregate on the same host plant can cause increased production of winged individuals (Lamb and MacKay, 1987), but this is likely to reflect a density-dependent response. In contrast, the mere presence of particular natural enemies may elicit an increase in winged morph production in the pea aphid, Acyrthosiphon pisum (Dixon and Agarwala, 1999; Weisser et al, 1999; Sloggett and Weisser, 2002; Kunert and Weisser, 2003) (parasitization may also directly affect wing development, see below). The induction of winged morphs seems to result from increased tactile stimulation triggered by either predator avoidance behavior or from the release of aphid alarm pheromone (Kunert et al, 2005). The presence of ants (which provide some protection for aphids against predators) seems to inhibit the production of winged individuals (El-Ziady and Kennedy, 1956; Kleinjan and Mittler, 1975). Aphid or plant pathogens (eg, fungi or viruses) and the facultative aphid endosymbionts may also affect wing induction (Müller et al, 2001; Leonardo and Mondor, 2006).

Abiotic factors: Several other factors, in particular temperature, may influence wing production either directly or indirectly via the host plant (White, 1946; Kenten, 1955; Johnson and Birks, 1960; Schaefers and Judge, 1971; Liu, 1994). Most studies have reported a decline in winged morph production as temperature increases (Müller et al, 2001). Photoperiod may be responsible for wing induction of parthenogenetic females in clones that do not undergo sexual reproduction (Lees, 1966).

\section{Maternal effects}

In addition to environmental factors, several maternal and transgenerational influences affect winged morph determination. In many species where wing determination occurs prenatally (in parthenogenetic embryos carried within adults), winged adults rarely or never produce winged offspring (Lees, 1961; Sutherland, 1970). Similarly, early born progeny descended from winged mothers exhibit a decreased production of winged morphs (Mackay and Wellington, 1977). In contrast, early born (wingless) progeny derived from wingless mothers respond strongly to wing-inducing stimuli (Mackay and Wellington, 1977; MacKay and Lamb, 1979). Grand-maternal phenotype, maternal phenotype, and age therefore all affect and modulate the response to wing-inducing environmental conditions.

\section{Development}

The development of alternative phenotypes has been examined in several aphid species using histological methods (Shull, 1938; White, 1946; Kitzmiller, 1951; Johnson and Birks, 1960; Tsuji and Kawada, 1987a; Ganassi et al, 2005). Wing development appears to be the default developmental pathway and the wingless phenotype develops by diversion from this developmental pathway during prenatal or postnatal development. For example, Johnson and Birks (1960) examined a large number of fully developed embryos and first instar nymphs of Aphis craccivora and found wing anlagen in all of them, irrespective of whether or not they were destined to develop into winged adults. In this species, wing anlagen first appear as hypodermal thickenings shortly before the embryonic moult (Johnson, 1958a), which takes place about one day before birth. The wing buds increase in size until the embryo hatches from the mother. In nymphs destined to be wingless, the anlagen cease development at this stage. A similar scenario has been described in the pea aphid where all embryos, firstinstar nymphs and second-instar nymphs exhibit wing buds, which subsequently degenerate in the developing wingless morph (Tsuji and Kawada, 1987a).

Intermediates between winged and wingless phenotypes also occur rarely. Such intermediates may be wingless but show some morphological features of the winged morph or they may be winged without having flight muscles and show morphological characteristics of the wingless morph. In the case of Aphis fabae and other species, these intermediates can be induced when winginducing stimuli are removed at different time points of nymphal development (Shaw, 1970b). Furthermore, parasitoids that lay their eggs in adult aphids affect the wing development of offspring. Such offspring very frequently show an intermediate winged-wingless phenotype and wing development is inhibited in presumptive winged individuals (Johnson, 1958b, 1959; Christiansen-Weniger and Hardie, 1998, 2000).

\section{The role of hormones in the expression of the wing polyphenism}

\section{Juvenile hormone}

The observation that wingless adults and nymphs are morphologically similar led early workers to suggest that high titers of juvenile hormone (JH) induce the wingless state by promoting the retention of juvenile features in adults (Lamb, 1956; Johnson, 1959; Kennedy and Stroyan, 1959). Naturally occurring JHs, as well as crude JHcontaining extracts, $\mathrm{JH}$ precursors, and $\mathrm{JH}$ analogs have all been tested for their ability to inhibit the induction of 
winged morphs when administered to mothers carrying parthenogenetic embryos and to nymphs.

These studies have yielded disparate and sometimes conflicting results (Hardie and Lees, 1985), in part due to mistaking mere juvenilization by $\mathrm{JH}$ for authentic apterization (Lees, 1977), but also because of differences in species, dosages, means of administration, and experimental design. One clear result concerns the migratory winged morphs that produce sexual females, which in certain species (eg, A. fabae) can be induced by short days. Both long days and natural JHs administered to first- and early second-instar nymphs of these individuals cause them to develop as wingless morphs (Hardie, 1980, 1981). This appears, however, to be a special case - unrelated to the summer wing polyphenisms - in which $\mathrm{JH}$ is able to mimic the effect of long days. Indeed, the effects of both long days and JH can be cancelled out by crowding, suggesting that something other than or in addition to $\mathrm{JH}$ mediates the density-cued wing polyphenism (Hardie, 1980).

Attempts to correlate the activity of the organ that secretes $\mathrm{JH}$, the corpus allatum, with the production of wingless morphs have also yielded equivocal results. Several studies showed that third- and fourth-instar nymphs without wing buds possess larger corpora allata, either by volume or nuclei diameter (White, 1965, 1968, 1971; Lamb and White, 1971; Elliot, 1975). In at least one other species, however, this correlation does not hold (Leckstein and Llewellyn, 1975; Leckstein, 1976) and the working assumption that volume or nuclei diameter are suitable proxies for either corpus allatum secretory activity or JH titer may be invalid (Hardie and Lees, 1985). Attempts to measure JH directly have detected JH III at very low levels in Megoura viciae (Hardie et al, 1985), but no study has successfully correlated JH titers with the production of wingless morphs.

\section{Precocenes}

The failure to unequivocally induce or correlate winglessness with $\mathrm{JH}$ led to the proposal that the use of anti$\mathrm{JH}$ compounds or experimental destruction of the corpus allatum might break the experimental impasse (Hales, 1976). Cells of the corpus allatum are selectively destroyed by the plant-derived precocenes, Precocene I (PI) and Precocene II (PII), as well as the more potent synthetic precocene, Precocene III (PIII) (Ohta and Bowers, 1977). In sensitive species, precocene treatment thus prevents $\mathrm{JH}$ synthesis and results in the precocious appearance of adult characteristics in nymphal instars (Brooks and McCaffery, 1990). Consistent with a predicted role for $\mathrm{JH}$ in mediating the aphid wing polyphenism, PII applied to mothers can induce the entire suite of characteristics found in the winged morph in her parthenogenetic offspring (Mackauer et al, 1979; Delisle et al, 1983; Hardie, 1986; Rup and Sohal, 1989; Hardie et al, 1995, 1996; Gao and Hardie, 1996). However, PIII is capable of inhibiting the production of winged morphs, at least in the pea aphid (Hardie et al, 1995; Gao and Hardie, 1996).

Despite what is generally understood about the targets of precocenes, their contradictory effects on winged morph induction are probably not mediated by $\mathrm{JH}$. Although PII is able to induce winged progeny in several species, the majority of studies suggest that it fails to induce precocious development, the classic JH-mediated hallmark of precocenes (Mackauer et al, 1979; Delisle et al, 1983; Hardie, 1986; Hardie et al, 1995, 1996). Consistent with this result, $\mathrm{JH}$ generally fails to reverse the winged morph-inducing effects of PII (Hardie, 1986; Hardie et al, 1995; Gao and Hardie, 1996). Moreover, although the inhibition of winged morph production caused by PIII is accompanied by precocious development and destruction of the corpus allatum (Hales and Mittler, 1981; Kambhampati et al, 1984; Hardie, 1986; Hardie et al, 1995, 1996), the application of JH is capable of rescuing precocious development without reversing the inhibition of winged morphs (Gao and Hardie, 1996). Together, these observations suggest that PII and PIII exert their effects on the wing polyphenism independently of $\mathrm{JH}$, and that the target mediating the effect of precocene on winged morph production remains unknown.

These results for precocenes, as well as a dearth of clear positive evidence for regulation by $\mathrm{JH}$, leave the question of hormonal regulation of wing induction unanswered. Other than one study reporting a negative result for ecdysterone (Applebaum et al, 1975), no other hormonal candidates for mediating the wing polyphenism have been investigated. This despite the likely requirement, for species showing prenatal induction, that the morph-determining signal must be able to cross the haemolymph. In seeking other candidates, it is perhaps worth keeping in mind one old but telling result for both Aphis craccivora and Megoura viciae; decapitation of females that have been cued to produce winged offspring leads to the almost immediate and exclusive production of wingless morphs. This suggests that signals either from the brain or the corpus allatum of the mother are likely to induce winged characteristics and not to suppress them as the JH model suggests (Johnson and Birks, 1960; Lees, 1966).

\section{Evolution}

Origin and maintenance of alternative phenotypes

For most organisms displaying alternative phenotypes, neither phenotype exhibits higher fitness overall. Rather, there is a trade-off, with the relative fitness of the different phenotypes being contingent upon environmental conditions. The evolution and maintenance of alternative phenotypes therefore requires variation in the environment. In aphids and many other wing-dimorphic insects, the winged morph usually has a lower individual fecundity than the wingless morph. In the face of deteriorating conditions, however, the ability to disperse may grant the winged morph an advantage. The wing polyphenism and other alternative phenotypes enable aphid clones to specialize for different environments and functions. As aphids produce alternative phenotypes within a genetic clone, there is no genetic conflict among individuals and selection should act to optimize investment in alternative phenotypes.

The evolution of polyphenism requires several conditions. First, environmental conditions must influence development to generate different phenotypes. Second, the resulting phenotypes must exhibit higher than average fitness in their respective environments. The factors acting as cues may be the same as the selective 
agents or may be different. As the developmental environment precedes the selective environment, an environmental cue must at least be correlated with future selective factors. Environmental control of alternative phenotypes can therefore evolve in organisms living in spatially or temporally variable environments in which cues can be used to reliably predict the future selective environment (Moran, 1992). It is possible that polyphenisms originated as polymorphisms that accumulated environmental influences (West-Eberhard, 2003). Aphids are particularly well suited for addressing this question because in some species the male wing dimorphism is genetically determined.

\section{Male wing polymorphism in the pea aphid}

Winged and wingless males of the pea aphid are found both in the ancestral range of Europe and in introduced populations of North America (Meier, 1958; Müller, 1962; Cartier, 1963; Hille Ris Lambers, 1966; Blackman and Eastop, 1994, 2000). The male polymorphism is controlled by a single locus on the $X$ chromosome called aphicarus (api) (Smith and MacKay, 1989; Caillaud et al, 2002; Braendle et al, 2005a). In aphids, males are haploid for the $\mathrm{X}$ chromosome, so one allele of api causes winged males and the other causes wingless males. Given that males are produced only for a short period of time in the autumn, a lack of available environmental cues might explain why the male polymorphism relies upon a genetic switch.

Three api genotypes are present in natural populations: clones homozygous for the api-winged allele that produce all winged males, clones homozygous for the api-wingless allele that produce all wingless males and clones heterozygous for api that produce winged and wingless males in equal proportions. Although all three possible api genotypes may occur on the same host plant species, several studies suggest that male morph production may correlate with host plant range and persistence (Meier, 1958; Müller, 1962; Markkula, 1963; Eastop, 1971). The precise costs and benefits of producing winged versus wingless males are not known. Only winged males can move long distances to find mates on distant host plants. On the other hand, wingless males develop more quickly than winged males and may outcompete winged males born on the same host plant. There may therefore be specific advantages associated with each morph.

\section{Genetic variation for the wing polyphenism}

Different clones of the pea aphid, Acyrthosiphon pisum (Markkula, 1963; Lowe and Taylor, 1964; Weisser and Braendle, 2001; Hazell et al, 2005; Braendle et al, 2005b), and other species (MacGillivray and Anderson, 1958; Kvenberg and Jones, 1974; Blackman, 1979; Groeters, 1989) display variation in the propensity to produce winged females, even when exposed to the same environmental conditions. It is not yet known whether this genetic variation in the plastic response to environmental cues is adaptive. Some of this variation may be related to the host plant preferences of aphid clones (MacGillivray and Anderson, 1958; Weisser and Braendle, 2001), yet variation is also observed in clones collected from the same host plant species (Braendle et al, 2005b).
Relationship between female wing polyphenism and male wing polymorphism

As the female wing polyphenism mimics phenotypes generated by the male wing polymorphism, one question is whether the genotype-environment interaction associated with the polyphenism involves the same loci that control the polymorphism. We have started to test this possibility by examining the wing-induction tendencies of the three possible api genotypes (Braendle et al, 2005b). We derived $F_{2}$ clones from a cross between parental clones homozygous for the two api alleles, which randomized alleles at loci that were not closely linked to api. In every case, clones homozygous for the apiwinged allele produced few winged females. In contrast, clones heterozygous for api or homozygous for the apiwingless allele produced comparatively large numbers of winged females. In other words, alleles of the api locus producing the male winged morph and unknown loci influencing female wing plasticity are genetically linked in opposite phase. We do not know the extent of the linkage between api and the factors contributing to variation in wing polyphenism, but in the extreme they could represent pleiotropic effects of api. One important caveat of this work is that this linkage has been found in progeny derived from a single cross of two wild lines homozygous for the two api alleles. Without analyzing a larger sample of clones segregating for the different api alleles, we do not yet know if the genetic variation for the female polyphenism and api are in linkage disequilibrium in natural populations.

\section{Future directions}

The wing polyphenism in aphids provides a clear example of adaptive phenotypic plasticity. The coexpression of a wing polyphenism (females) and a wing polymorphism (males) in the pea aphid provides a rare opportunity to address the relationship between environmental and genetic induction of alternative phenotypes. This may also help to clarify how genetic and environmental factors interchangeably control the same developmental events, and how evolutionary transitions between polyphenisms and polymorphisms take place. From a practical point of view, the identification of genes involved in the polymorphic control of alternative phenotypes may facilitate the study of a polyphenism displaying a similar set of alternative phenotypes.

Aphid ecology and physiology have been studied intensively during the past few decades but little is known about the genetics and development underlying the expression of alternative phenotypes. Currently, aphids are becoming an increasingly important model system because a large community has begun to develop genomic resources for the pea aphid, Acyrthosiphon pisum. Perhaps most importantly, the genome of the pea aphid is currently being sequenced at the Human Genome Sequencing Center at Baylor College of Medicine with funds provided by the National Human Genome Research Institute (www.hgsc.bcm.tmc.edu/ projects/aphid/). These resources will provide novel opportunities for investigating the aphid wing dimorphism and many other features of aphid biology, such as aphid-plant interactions and the relationship between aphids and their endosymbiotic bacteria. 


\section{Acknowledgements}

$\mathrm{CB}$ acknowledges support from the Boehringer Ingelheim Fonds, Roche Research Foundation and the Swiss National Science Foundation. GKD acknowledges support from the NIH for a NRSA post-doctoral fellowship. DLS acknowledges support from the NIH (Grant GM6362201), Princeton University and the David and Lucile Packard Foundation.

\section{References}

Applebaum SW, Raccah B, Leiserowitz R (1975). Effect of juvenile hormone and $\beta$-ecdysone on wing determination in the aphid Myzus persicae. J Insect Physiol 21: 1279-1281.

Blackman RL (1979). Stability and variation in aphid clonal lineages. Biol J Linnean Soc 11: 259-277.

Blackman RL, Eastop VF (1994). Aphids on the World's Trees: An Identification and Information Guide. CAB International: Wallingford.

Blackman RL, Eastop VF (2000). Aphids on the World's Crops: An Identification and Information Guide. John Wiley \& Sons Ltd.: Chichester.

Bonnemaison L (1951). Contribution à l'étude des facteurs provoquant l'apparition des formes ailées et sexuées chez les Aphidinae. Ann Epiphyt 2: 1-380.

Braendle C, Caillaud MC, Stern DL (2005a). Genetic mapping of aphicarus - a sex-linked locus controlling a wing polymorphism in the pea aphid (Acyrthosiphon pisum). Heredity 94: 435-442.

Braendle C, Friebe I, Caillaud MC, Stern DL (2005b). Genetic variation for an aphid wing polyphenism is genetically linked to a naturally occurring wing polymorphism. Proc Biol Sci 272: 657-664.

Brooks GT, McCaffery AR (1990). The precocene antijuvenile hormones (Allatotoxins): A case history in insect toxicology. In: McCaffery AR and Wilson ID (eds) Chromatography and Isolation of Insect Hormones and Pheromones. Plenum Press: New York. pp 33-43.

Caillaud CM, Boutin M, Braendle C, Simon JC (2002). A sexlinked locus controls wing polymorphism in males of the pea aphid, Acyrthosiphon pisum (Harris). Heredity 89: 346-352.

Campbell A, Mackauer M (1977). Reproduction and population growth of the pea aphid (Homoptera: Aphididae) under laboratory and field conditions. Can Entomol 109: 277-284.

Cartier JJ (1963). Les formes du puceron du pois dans le sud du Quebec. Can Entomol 95: 558-560.

Christiansen-Weniger P, Hardie J (1998). Wing development in parasitized male and female Sitobion fragariae. Physiol Entomol 23: 208-213.

Christiansen-Weniger P, Hardie J (2000). The influence of parasitism on wing development in male and female pea aphids. I Insect Physiol 46: 861-867.

Delisle J, Cloutier C, McNeil JN (1983). Precocene II-induced alate production in isolate and crowded alate and apterous virginoparae of the aphid, Macrosiphum euphorbiae. J Insect Physiol 29: 477-484.

Dixon AFG (1972). Fecundity of brachypterous and macropterous alatae in Drepanosiphum dixoni (Callaphidae, Aphididae). Entomol Exp Applicata 15: 335-340.

Dixon AFG, Agarwala BK (1999). Ladybird induced life history changes in aphids. Proc R Soc Lond-Biol Sci 266: 1549-1553.

Eastop VF (1971). Keys for the identification of Acyrthosiphon. Bull Brit Mus (Natural History) Entomol 26: 1-115.

El-Ziady S, Kennedy JS (1956). Beneficial effects of the common garden ant, Lasius niger L., on the black bean aphid, Aphis fabae Scop. Proc R Entomol Soc Lond 31: 61-65.

Elliot HJ (1975). Corpus allatum and ovarian growth in a polymorphic paedogenetic insect. Nature 257: 390-391.
Ganassi S, Signa G, Mola L (2005). Development of the wing buds in Megoura viciae: a morphological study. Bull Insectol 58: 101-105.

Gao N, Hardie J (1996). Pre- and post-natal effects of precocenes on aphid morphogenesis and differential rescue. Arch Insect Biochem Physiol 32: 503-510.

Groeters FR (1989). Geographic and clonal variation in the milkweed-oleander aphid, Aphis nerii (Homoptera: Aphididae), for winged morph production, life history, and morphology in relation to host plant permanence. Evol Ecol 3: 327-341.

Hales DF (1976). Juvenile hormone and aphid polymorphism. In: Lüscher M (ed) Phase and Caste Determination in Insects. Pergamon Press: Oxford. pp 105-115.

Hales DF, Mittler TE (1981). Precocious metamorphosis of the aphid Myzus persicae induced by the precocene analogue 6-methocy-7-ethoxy-2,2-dimethylchromene. J Insect Physiol 27: 333-337.

Hardie J (1980). Juvenile hormone mimics the photoperiodic apterization of the alate gynopara of aphid, Aphis fabae. Nature 286: 602-604.

Hardie J (1981). Juvenile hormone and photoperiodically controlled polymorphism in Aphis fabae: postnatal effects on presumptive gynoparae. I Insect Physiol 27: 347-355.

Hardie J (1986). Morphogenetic effects of precocenes on three aphid species. I Insect Physiol 32: 813-818.

Hardie J, Baker FC, Jamieson GC, Lees AD, Schooley DA (1985). The identification of an aphid juvenile hormone, and its titre in relation to photoperiod. Physiol Entomol 10: 297-302.

Hardie J, Gao N, Timár T, Sebók P, Honda K (1996). Precocene derivatives and aphid morphogenesis. Arch Insect Biochem Physiol 32: 493-501.

Hardie J, Honda K, Timár T, Varjas L (1995). Effects of 2,2dimethylchromene derivatives on wing determination and metamorphosis in the pea aphid, Acyrthosiphon pisum. Arch Insect Biochem Physiol 30: 25-40.

Hardie J, Lees AD (1985). Endocrine control of polymorphism and polyphenism. In: Kerkut GA and Gilbert LJ (eds) Insect Physiology, Biochemistry and Pharmacology. Pergamon Press: New York. pp 441-490.

Hazell SP, Gwynn DM, Ceccarelli S, Fellowes MDE (2005). Competition and dispersal in the pea aphid: clonal variation and correlations across traits. Ecol Entomol 30: 293-298.

Heie OE (1982). The Aphidoidea (Hemiptera) of Fennoscandia and Denmark II The family Drepanosiphidae. Scandinavian Science Press Ltd.: Klampenborg.

Heikinheimo O (1987). Wing polymorphism in Symydobius oblongus (Von Heyden, 1837) and Myzocallis myricae (Kaltenbach, 1843). In: Holman J, Pelikan J, Dixon AFG and Weismann L (eds) Population Structure, Genetics and Taxonomy of Aphids and Thysanoptera. SPB Academic Publishing: Smolenice. pp 170-175.

Hille Ris Lambers D (1947). Contributions to a monograph of the Aphididae of Europe III. Temminckia 7: 179-319.

Hille Ris Lambers D, van den Bosch R (1964). On the genus Therioaphis Walker, 1870, with descriptions of new species (Homoptera, Aphididae). Zool Verhandlungen 68: 3-47.

Hille Ris Lambers L (1966). Polymorphism in the Aphididae. Annu Rev Entomol 11: 47-78.

Johnson B (1958a). Embryonic cuticle in aphids. Aus J Sci 21: 146.

Johnson B (1958b). Influence of parasitization on form determination in aphids. Nature 181: 205-206.

Johnson B (1959). Effect of parasitization by Aphidius platensis Bréthes on the developmental physiology of its host Aphis craccivora Koch. Entomol Exp Applicata 2: 82-99.

Johnson B (1965). Wing polymorphism in aphids II. Interaction between aphids. Entomol Exp Applicata 8: 49-64.

Johnson B, Birks PR (1960). Studies on wing polymorphism in aphids I. The developmental process involved in the 
production of the different forms. Entomol Exp Applicata 3: 327-339.

Kalmus H (1945). Correlations between flight and vision, and particularly between wings and ocelli, in insects. Proc $R$ Entomol Soc London A 20: 84-96.

Kambhampati S, Mackauer M, Nair KK (1984). Precocious metamorphosis and wing formation in the pea aphid Acyrthosiphon pisum, induced by precocene analogue 7ethoxy-6methoxy-2,2-dimethylchromene. Arch Insect Biochem Physiol 1: 115-147.

Kawada K (1987). Polymorphism and morph determination. In: Minks AK and Harrewijn P (eds) Aphids, Their Biology, Natural Enemies and Control. Elsevier: Amsterdam. pp 255-266.

Kennedy JS, Stroyan HLG (1959). Biology of aphids. Annu Rev Entomol 4: 139-160.

Kenten J (1955). The effect of photoperiod and temperature on reproduction in Acyrthosiphon pisum (Harris) and on the forms produced. Bull Entomol Res 46: 599-624.

Kitzmiller JB (1951). The time interval between determination and differentiation of wings, ocelli, and wing muscles in the aphid Macrosiphum sanborni (Gillette). Am Natural 84: 23-50.

Kleinjan JE, Mittler TE (1975). A chemical influence of ants on wing development in aphids. Entomol Exp Applicata 18: 384-388.

Kring JB (1977). Structure of the eyes of the pea aphid, Acyrthosiphon pisum. Ann Entomol Soc Am 70: 855-860.

Kunert G, Otto S, Rose SR, Gershenzon J, Weisser WW (2005). Alarm pheromone mediates production of winged dispersal morphs in aphids. Ecol Lett 8: 596-603.

Kunert G, Weisser WW (2003). The interplay between densityand trait-mediate effects in predator-prey interactions: a case study in aphid wing polymorphism. Oecologia 135: 304-312.

Kunert G, Weisser WW (2005). The importance of antennae for pea aphid wing induction in the presence of natural enemies. Bull Entomol Res 95: 125-131.

Kunkel H, Kloft W (1974). Polymorphismus bei Blattläusen. In: Schmidt GH (ed) Sozialpolymorphismus bei Insekten. Wissenschaftliche Verlagsgesellschaft: Stuttgart. pp 152-201.

Kvenberg JE, Jones PA (1974). Comparison of alate offspring produced by two biotypes of the greenbug. Env Entomol 3: 407-408.

Lamb KP (1956). Physiological Relations Between Aphids and Their Host Plants, pp. Cambridge University: Cambridge, England

Lamb RJ, MacKay PA (1987). Acyrthosiphon kondoi influences alata production by the pea aphid A. pisum. Entomol Exp Applicata 45: 195-204.

Lamb KP, White DF (1971). Endocrine aspects of alary polymorphism in Brevicoryne brassicae (L.). Endocrinol Exp 5: 19-22.

Leckstein PM (1976). The role of the corpus allatum in prenatal wing determination in Megoura viciae. J Insect Physiol 22: 1117-1121.

Leckstein PM, Llewellyn M (1975). Corpus allatum activity and wing determination in Megoura viciae. Nature 258: 714-715.

Lees AD (1961). Clonal polymorphism in aphids. In: Kennedy JS (ed) Insect Polymorphism. Royal Entomological Society: London. pp 68-79.

Lees AD (1966). The control of polymorphism in aphids. Adv Insect Physiol 3: 207-277.

Lees AD (1967). The production of the apterous and alate forms in the aphid Megoura viciae Buckton, with special reference to the role of crowding. I Insect Physiol 13: 289-318.

Lees AD (1977). Action of juvenile hormone mimics on the regulation of larval-adult and alary polymorphisms in aphids. Nature 267: 46-48.

Leonardo TE, Mondor EB (2006). Symbiont modifies host lifehistory traits that affect gene flow. Proc R Soc B-Biol Sci 273 1079-1084.

Liu S-S (1994). Production of alatae in response to low temperature in aphids: a trait of seasonal adaptation. In:
Danks HV (ed) Insect Life-Cycle Polymorphism: Theory, Evolution, and Ecological Consequences for Seasonality and Diapause Control. Kluwer Academic Publishers: Dordrecht. pp 245-261.

Lowe HJB, Taylor LR (1964). Population parameters, wing production and behaviour in red and green Acyrthosiphon pisum (Harris) (Homoptera: Aphididae). Entomol Exp Applicata 7: 287-295.

MacGillivray ME, Anderson GB (1958). Production of apterous and alate progeny by apterous and alate viviparae of Macrosiphum solanifolii (Ashm.) (Homoptera: Aphididae). Can Entomol 90: 241-245.

Mackauer M, Nair KK, Unnithan GC (1979). Effect of precocene II on alate production in the pea aphid, Acyrthosiphon pisum. Can J Zool 57: 856-859.

MacKay PA, Lamb RJ (1979). Migratory tendency in aging populations of the pea aphid, Acyrthosiphon pisum. Oecologia 39: 301-308

MacKay PA, Reeleder DJ, Lamb RJ (1983). Sexual morph production by apterous and alate viviparous Acyrthosiphon pisum (Harris) (Homoptera: Aphididae). Can J Zool 61: 952-957.

MacKay PA, Wellington WG (1975). A comparison of the reproductive patterns of apterous and alate virginoparous Acyrthosiphon pisum (Homoptera: Aphididae). Can Entomol 107: 1161-1166.

Mackay PA, Wellington WG (1977). Maternal age as a source of variation in the ability of an aphid to produce dispersing forms. Res Popul Ecol 18: 195-209.

Markkula M (1963). Studies on the pea aphid, Acyrthosiphon pisum Harris (Hom., Aphididae), with special reference to the differences in the biology of the green and red forms. Ann Agriculturae Fenniae 2: 1-30.

Meier W (1958). Beiträge zur Kenntnis der auf Papilionaceen lebenden Acyrthosiphon-Arten (Hemipt. Aphid). Mitteilungen der Schweizerischen Entomologischen Gesellschaft 31: 291-312.

Mittler TE, Sutherland ORW (1969). Dietary influences on aphid polymorphism. Entomol Exp Applicata 12: 703-713.

Miyazaki M (1987). Forms and morphs of aphids. In: Minks AK and Harrewijn P (ed) Aphids, Their Biology, Natural Enemies and Control. Elsevier: Amsterdam. pp 163-195.

Moran NA (1992). The evolutionary maintenance of alternative phenotypes. Am Natural 139: 971-989.

Müller CB, Williams IS, Hardie J (2001). The role of nutrition, crowding and interspecific interactions in the development of winged aphids. Ecol Entomol 26: 330-340.

Müller FP (1962). Biotypen und Unterarten der 'Erbsenlaus' Acyrthosiphon pisum (Harris). Z Pflanzenkrankheiten Pflanzenschutz 69: 129-136.

Müller FP (1969). Bastardierungsversuche zur Feststellung von Isolierungsmechanismen zwischen nahe verwandten Formen in der Gattung Myzus Passerini (Homoptera: Aphididae). Biol Zentralblatt 88: 147-164.

Noda I (1960). The emergence of winged viviparous female in aphid. - VI. Difference in rate of development between the winged and unwinged forms. Jap J Appl Entomol Zool 10: $97-102$

Nunes MV, Hardie J (1996). Differential photoperiodic responses in genetically identical winged and wingless pea aphid, Acyrthosiphon pisum, and the effect of day length on wing development. Physiol Entomol 21: 339-343.

Ohta T, Bowers WS (1977). Synthesis of insect antijuvenile hormones. Chem Pharm 25: 2788-2789.

Rup BJ, Sohal SK (1989). Morphogenetic effects of precocene II on Lipaphis erysimi (Homoptera, Aphididae). Acta Entomol Bohemoslov 86: 172-178.

Schaefers GA, Judge FD (1971). Effects of temperature, photoperiod, and host plant on alary polymorphism in the aphid, Chaetosiphon fragaefolii. J Insect Physiol 17: 365-379.

Shaw MJP (1970a). Effect of population density on alienocolae of Aphis fabae Scop. I. The effect of crowding on the 
production of alatae in the laboratory. Ann Appl Biol 65: 191-196.

Shaw MJP (1970b). Effect of population density on alienocolae of Aphis fabae Scop. III. The effect of isolation on the development of form and behaviour of alatae in a laboratory clone. Ann Appl Biol 65: 205-212.

Shull AF (1938). Time of determination and time of differentiation of aphid wings. Am Natural 72: 170-179.

Sloggett JJ, Weisser WW (2002). Parasitoids induce production of the dispersal morph of the pea aphid, Acyrthosiphon pisum. Oikos 98: 323-333.

Smith MAH, MacKay PA (1989). Genetic variation in male alary dimorphism in populations of pea aphid, Acyrthosiphon pisum. Entomol Exp Appl 51: 125-132.

Sutherland ORW (1969a). The role of crowding in the production of winged forms by two strains of the pea aphid, Acyrthosiphon pisum. J Insect Physiol 15: 1385-1410.

Sutherland ORW (1969b). The role of the host plant in the production of winged forms by two strains of the pea aphid, Acyrthosiphon pisum. J Insect Physiol 15: 2179-2201.

Sutherland ORW (1970). An intrinsic factor influencing the alate production by two strains of the pea aphid, Acyrthosiphon pisum. I Insect Physiol 16: 1349-1354.

Tsuji H, Kawada K (1987a). Development and degeneration of wing buds and indirect flight muscles in the pea aphid (Acyrtosiphon pisum (Harris)). Jap J Appl Entomol Zool 31: 247-252.

Tsuji H, Kawada K (1987b). Effects of starvation on life span and embryo development of four morphs of pea aphid (Acyrthosiphon pisum (Harris)). Jap J Appl Entomol Zool 31: 36-40.
Tsumuki H, Nagatsuka H, Kawada K, Kanehisa K (1990). Comparison of nutrient reservation in apterous and alate pea aphids, Acyrthosiphon pisum (Harris). 1. Developmental time and sugar content. Appl Entomol Zool 25: 215-221.

Vereschagina AB, Shaposhnikov GC (1998). Influence of crowding and host-plant on development of winged and apterous aphids. In: Nieto Nafrio JM and Dixon AFG (ed) Aphids in Natural and Managed Ecosystems. Universidad de Leon: Leon, Spain.

Waloff N (1983). Absence of wing polymorphism in the arboreal, phytophagous species of some taxa of temperate Hemiptera - A hypothesis. Ecol Entomol 8: 229-232.

Weisser WW, Braendle C (2001). Body colour and genetic variation in winged morph production in the pea aphid. Entomol Exp Applicata 99: 217-223.

Weisser WW, Braendle C, Minoretti N (1999). Predator-induced morphological shift in the pea aphid. Proc R Soc Lond B $\mathbf{2 6 6}$ 1175-1181.

West-Eberhard MJ (2003). Developmental Plasticity and Evolution. Oxford University Press: Oxford.

White DF (1965). Changes in size of corpus allatum of a polymorphic insect. Nature 208: 807.

White DF (1968). Cabbage aphid - effect of isolation on form and on endocrine activity. Science 159: 218-219.

White DF (1971). Corpus allatum activity associated with development of wingbuds in cabbage aphid embryos and larvae. I Insect Physiol 17: 761-773.

White WS (1946). The environmental conditions affecting the genetic mechanism of wing production in the chrysanthemum aphid. Am Natural 80: 245-270. 